\title{
Public health practitioners' perspective on the sustainability of the tuberculosis control programme at primary health care level in Pakistan
}

Syed Mustafa Ali $^{1}$ and Satwinder Rehal ${ }^{1}$

Faculty of Health and Life Sciences, University of Liverpool, Liverpool, United Kingdom. (Correspondence to: Syed Ali: mustafa_30_84@yahoo.com)

\begin{abstract}
Background: In resource-limited settings, national tuberculosis (TB) control programmes are highly dependent on external funds, which may pose a challenge to programme sustainability. There is a recognized need for developing guidance around sustainable programming of current TB control initiatives.
\end{abstract}

Aims: The aim of this study was to explore public health practitioners' perspectives on the sustainability of TB control initiatives in Pakistan at the primary health care (PHC) level.

Methods: Guided by an interpretive epistemology, online in-depth interviews were conducted with 10 public health practitioners who had experience as resource planners in the TB control programme in Pakistan. Thematic content analysis was employed to the textual data as the analytical approach.

Results: Three themes were inductively derived from the thematic analysis: community involvement, stakeholder engagement and efficient use of the PHC system. Community involvement was a determinant in sustaining TB control initiatives. This was attributed to the nature of the disease and prevalent health seeking behaviour. Stakeholder engagement was associated with funding arrangements between public and private partners and considered important in how new initiatives can be made part of the routine structure. Overall, having an efficient PHC system was deemed critical in sustaining current TB control initiatives at the PHC level in Pakistan.

Conclusion: Fostering an enabling operational environment through regulations, supporting the utilization of existing resources, expanding the network of providers, inclusive planning, increasing spending on research and cost-effective testing are pivotal for sustaining the TB control initiatives.

Keywords: tuberculosis, sustainable programming, TB control, Pakistan, primary health care

Citation: Ali S; Rehal S. Public health practitioners' perspective on the sustainability of the tuberculosis control programme at primary health care level in Pakistan. East Mediterr Health J. 2021;27(9):899-905. https://doi.org/10.26719/emhj.21.044

Received: 10/09/20; accepted: 01/03/21

Copyright @ $@$ World Health Organization (WHO) 2021. Open Access. Some rights reserved. This work is available under the CC BY-NC-SA 3.0 IGO license (https://creativecommons.org/licenses/by-nc-sa/3.o/igo).

\section{Introduction}

According to the Global TB Report of 2020, Pakistan is one of 30 high tuberculosis (TB) burden countries with an incidence rate of 570000 cases per year and 357893 new and relapse cases (2018 cohort) (1). This means that a significant proportion of cases ( 200 000) are missed, posing a significant threat to public health in Pakistan.

Over the past few decades, Pakistan's National TB Control Programme has achieved a remarkable improvement in notification and successful treatment rates. These can be attributed to the adoption of the directly observed treatment short-course (DOTS) strategy from 1995 onwards, revival of the National TB Control Programme in 2001 and to financial contributions of government and its partners (2). However, adaptation in the managerial set-up of the National TB Control Programme and the continuation of technical and donor support will be important in achieving the sustainability of the programme.

Sustainability refers to the continuation of a programme after the initial efforts implementing it
$(3,4)$. In the public health discourse, sustainability of public health initiatives refers to the evaluation of longterm effects of public health programmes because they are implemented over a longer period (5). As Altman contends, sustainability remains a key challenge as most public health interventions are discontinued after the initial funds are exhausted (6).

The sustainability of public health programmes has gained attention among various stakeholders (researchers, donors, community partners, etc.) in the recent past (7) with the focus on understanding contextual factors in which interventions are embedded (5). Evidence suggests that sustainability of public health initiatives can only be achieved if primary health care $(\mathrm{PHC})$ is adequately emphasized, which is also true for Pakistan (8).

With the increasing global interest in sustainability of public health initiatives, programme managers in the TB control programme in Pakistan have recognized the need for developing understanding and guidance around sustainable programming of public health initiatives and have called on the government in regard to developing a 
sustainable approach (9). Therefore, the aim of this study is to explore public health practitioners' perspectives on the sustainability of TB control initiatives in PHC settings in Pakistan. This study will guide policy and programmatic decisions to support sustainable TB programming at the $\mathrm{PHC}$ level in Pakistan.

\section{Methods}

\section{Study design}

This research utilized an interpretivist approach, which acknowledges that reality is socially constructed within a context (10) through natural-style conversation (11). That is why we adopted an exploratory qualitative research design (12): it allowed us to explore the perceptions of public health practitioners regarding the sustainability of the TB control programme.

\section{Sampling and eligibility criteria}

Purposive sampling was employed to recruit public health practitioners from different types of organization, including governmental (national and provincial TB control programmes) and not-for-profit nongovernmental organizations. Purposive sampling was deemed appropriate for the study as it intends to yield in-depth understanding of information-rich cases (13).

Potential participants who met the following eligibility criteria were invited to take part in the study: having more than 5 years of work experience, either previously or currently, in programming of TB control and strategic health planning in Pakistan; either working or having worked at the national or provincial level; fluent in English or Urdu; able to take part in Skype-based interviews. The exclusion criteria included: having no or little experience of TB programming in Pakistan; and having no access to Skype.

\section{Recruitment}

E-mail invitations were sent to participants who met the inclusion criteria. A participant information sheet was shared and informed consent was sought via e-mail. A Skype interview was scheduled with the participants at a time and place of their convenience. Out of nineteen potential participants who were invited to take part in the study, 10 public health practitioners participated in the in-depth interviews. While some of the invited participants did not answer multiple reminders, 2 declined to take part in the study because of their work commitments. Ten in-depth interviews were conducted. The profile of the participants is given in Table 1.

\section{Data collection}

A semi-structured, in-depth interview was conducted with the use of an interview guide (available on request), which was developed from the relevant sources (3-5,7,8,14,15). Key questions are listed below.

- In pursuit of the Sustainable Development Goals, what is the importance of primary health care, with focus on tuberculosis control?

\begin{tabular}{|c|c|c|c|}
\hline \multicolumn{4}{|c|}{$\begin{array}{l}\text { Table i Profile of the participants: } 10 \text { public health } \\
\text { practitioners with experience in programming of } \\
\text { tuberculosis control and strategic health planning in } \\
\text { Pakistan }\end{array}$} \\
\hline Participant ID & Sex & $\begin{array}{c}\text { Organization } \\
\text { type }\end{array}$ & $\begin{array}{c}\text { Years of } \\
\text { experience }\end{array}$ \\
\hline GO20191130 & Male & Governmental & 20 \\
\hline GO20191201 & Male & Governmental & 25 \\
\hline GO20200111 & Male & Governmental & 16 \\
\hline $\mathrm{N}_{4} \mathrm{PNGO} 20191116$ & Male & Nongovernmental & 08 \\
\hline $\mathrm{N}_{4} \mathrm{PNGO} 20191207$ & Female & Nongovernmental & 14 \\
\hline $\mathrm{N}_{4} \mathrm{PNGO} 20191230$ & Male & Nongovernmental & 24 \\
\hline $\mathrm{N}_{4} \mathrm{PNGO} 20200201$ & Male & Nongovernmental & 06 \\
\hline GO20200205 & Male & Governmental & 23 \\
\hline $\mathrm{N}_{4} \mathrm{PNGO} 20200205$ & Male & Nongovernmental & 11 \\
\hline $\mathrm{N}_{4} \mathrm{PNGO} 20200219$ & Male & Nongovernmental & 15 \\
\hline
\end{tabular}

- What do you think sustainability is and why is sustainability important in today's world?

- What is your opinion of the sustainability of the TB control programme in Pakistan?

- What kind of sustainability challenges is national TB control facing and how can they be managed?

- Based on the discussion and in your opinion, can you name one or a few critical factors which are required for sustainability?

Skype interviews were conducted between November 2019 and February 2020. These interviews were video/ audio recorded with participant consent, and lasted between 30 and 45 minutes.

\section{Analytical approach}

Thematic analysis was employed to analyse the interview transcripts. This involved immersion into textual data and identification of emerging themes or ideas relevant to the area of inquiry (16).

\section{Ethical considerations}

Ethical clearance for the study was granted from the review board of the International Research Force in Pakistan and from the University of Liverpool's ethical review committee. Participants were allowed to withdraw from the study at any time without giving any reason. They were assured in regard to their privacy and the confidentiality of the data. Relevant records were anonymized (Table 1). No monetary compensation was given to participants.

\section{Results}

\section{Conceptions of sustainability}

The thematic content analysis included interviews with 10 public health practitioners with knowledge and experience of resource planning in the TB programme. The analysis of textual data highlighted 3 broad themes in 
relation to the understanding of the sustainability of $\mathrm{TB}$ control initiatives at the PHC level in Pakistan (Table 2).

Respondents tried to deconstruct the concept of sustainability based on their conceptualization. Most of the respondents viewed sustainability as the continuation of financial resources until TB is eliminated from Pakistan. However, an alternative conception of sustainability was elaborated as the maintenance of existing control efforts, as reflected in the quote below:

"Sustainability is more referring to continuity of that [existing] service ... about rest of $30-35 \%$ missing cases, how to reach this population is more of an innovation and expansion rather than sustainability." [N4PNGO20191230]

Given the conceptions on what sustainability meant to participants, this was constructed around the following 3 themes: an efficient PHC system, community involvement and stakeholder engagement.

\section{Efficient primary health care system}

Pakistan has an extended primary health care system that forms the backbone of the overall health care system. The importance of the PHC setup was also recognized in the Sustainable Development Goals by prioritizing PHC services and thinking beyond vertical programmes (17). One of the respondents reflected this as:

“... services at the grassroots level ... are normally curative and preventive in nature...these services actually proved beneficial to reach out the targeted population when you try to integrate the vertical programmes, just like TB or malaria." [N4PNGO20200219]

An efficient PHC system is elaborated through 2 subthemes: significance of the PHC system and health care system strengthening. The PHC system in Pakistan is the first level of health care, and comprises both public and private sector facilities. Most of the respondents recognized that the PHC system is critically important and without strengthening it further, sustainability in the TB control programme cannot be achieved.

"Primary health care set up is important ... [because] it is approachable and affordable to community ... and is a first point of contact ... strengthening this level is important for sustainability." [N4PNGO20191207]

The role of the PHC system is also significant in running advocacy campaigns that will allow for capacity-

\begin{tabular}{|c|c|}
\hline \multicolumn{2}{|c|}{$\begin{array}{l}\text { Table } 2 \text { List of themes and subthemes related to the study } \\
\text { topic: sustainability of the tuberculosis control programme } \\
\text { at primary health care (PHC) level in Pakistan }\end{array}$} \\
\hline Theme & Subtheme \\
\hline \multirow[t]{2}{*}{ Community involvement } & Health seeking behaviour \\
\hline & Contributions towards health care \\
\hline \multirow[t]{2}{*}{ Stakeholder engagement } & $\begin{array}{l}\text { Nature and institutionalization of } \\
\text { interventions }\end{array}$ \\
\hline & Funding arrangement \\
\hline \multirow{2}{*}{$\begin{array}{l}\text { Efficient primary health } \\
\text { care system }\end{array}$} & Significance of PHC system \\
\hline & Health care system strengthening \\
\hline
\end{tabular}

building among the community. One respondent gave an example:

"... they engaged schoolgirls and then they made them their TB advocates. They were given training on how to screen and later they were asked to do screening in their respective areas ..." [N4PNGO20191207]

\section{Health care system strengthening}

Most of the respondents mentioned the significance of reforms to develop and implement relevant guidelines. The need for building the capacity of health care professionals and improving referral linkages between health care facilities were recognized as important factors for identifying missing $\mathrm{TB}$ cases and sustaining the control efforts. One of the respondents said:

"... what type of patient, at what level of care and when to access specialized care ... so ... this type of [inequitable] system is not sustainable until we do reforms." [N4PNGO20191116]

For health system strengthening, innovations were accorded immense importance by the majority of the respondents. One respondent representing a government organization suggested:

“... private sector is needed to make interventions ... here the innovations are needed ... new experiments can be performed so this can be executed by the private sector ... at many times, we are so much restricted by regulations and also due to HR constraints that we cannot travel far and cannot leave facilities." [GO20191201]

\section{Community involvement}

From the analysed data, community involvement in TB control initiatives was conceptualized in the following 2 subthemes: health seeking behaviour and contributions towards health care.

\section{Health seeking behaviour}

Low education level, poor health awareness and the stigma associated with TB in Pakistan result in the development of negative health seeking behaviour.

Given the stigmatization of TB in Pakistan, raising disease awareness is considered particularly important for generating the demand for treatment. However, several of the respondents articulated that meaningful participation of community members is lacking in the current programming. One of the respondents said:

"A representative from the patient community ... is usually a handpicked person from the HIV community ... because CCM [forum] represents all 3 disease areas [malaria, TB and HIV] ... and I think there is little representation from the TB world ... Managers sort of making a call of what is needed rather than having a forum where ... you have some way of feeling back what is needed from the patients in their own perspectives." [N4PNGO202200205] 


\section{Contributions towards health care}

The cost of TB care is considered an important factor in the accessibility and acceptability of the TB care and prevention services in Pakistan. Increasingly, the published literature supports social protection schemes and policies; hardly any respondents had opposing views.

A few respondents had the opinion that community members exhibit non-responsible behaviour as they do not acknowledge the availability of free-of-cost services. Therefore, they supported the idea of a nominal contribution from the community towards health care costs.

“... we need to make our community realise that if they are provided with free-of-cost services, then they should acknowledge them rather than to condemn services and discourage continuity of treatment." [N4PNGO20191116]

In Pakistan, TB is prevalent among those who have low socioeconomic status and a low education level (18). Therefore, there is a need for raising awareness so that the demand for TB care and prevention services is created.

\section{Stakeholder engagement}

The End TB Strategy demands actions beyond the health ministry and emphasizes that the National Strategic Plan should be developed and implemented in close coordination and collaboration with all stakeholders (19). After stakeholders are identified, their roles and responsibilities and funding arrangements should be defined based on the nature of the interventions.

\section{Nature and institutionalization of interventions}

Sustainability concerns the institutionalization of the newly implemented interventions, and institutionalization depends on the extent of shared understanding of sustainability among different stakeholders (7). The majority of respondents considered the government of Pakistan, or the National TB Control Programme, as a prime stakeholder. The involvement of other functionaries, such as finance, economics, planning and development, was considered equally important. Other nongovernmental stakeholders identified were community-based organizations, faith-based organizations, professional associations, and global and bilateral donors, thus suggesting a multisectoral approach to planning and implementation.

Nearly all respondents agreed that the government's commitment has to be increased and funds allocation on the TB control programme should be prioritized, as illustrated by one respondent thus:

“... government says that health and education are our priorities in Pakistan and they allocate the lowest budgets for health and education sectors. So, now you [we] must have a clear idea about their priorities." [GO20200205]

In terms of sustainable TB control programmes, most of the respondents acknowledged the importance of the private health care sector and identified the need for utilizing existing resources, for which regulation is an important step. Therefore, programme design was given importance and expressed as:

"One key dimension of sustainability would be the programme design," and explained further as "Roles and responsibilities are assigned to individuals and [their] settings, which are regular structures, rather than project structures." [N4PNGO20191230]

Although respondents representing the government considered innovations as a means of engaging private sector organizations, they criticized the disproportionately high operational and human resource costs. An experienced resource planner within the TB control programme said:

"... active case finding ... there should be criteria about how long we are going to do this ... it should be decided which innovations are cost-effective ... and sustainable ... you [we] have not harvested low hanging fruits and instead we went for [cost-intensive] active case finding ... so we have to balance this specifically in the countries like us." [GO20191201]

Generally, innovations and research were ranked high among respondents, but one respondent expressed concern about the research situation in the TB control programme and said:

"If you start prioritizing funding/priority areas, then the component of research goes very down in that priority list ... and this is [the] reality of all low and middle income countries ..." [N4PNGO20200219]

\section{Funding arrangements}

With inadequate domestic funding and system-level inefficiencies, dependence on donors is recognized as a potential limiting factor for sustaining the TB control programme.

Implementation of the National Strategic Plan became challenging because of the competing interests among the public and private implementation organizations. This took away from the programme the opportunity to allow partners to complement each other.

Moreover, politicization of the funding process and donors supporting their own funding mechanism were seen as potential hindering factors in the implementation of the National Strategic Plan. One of the respondents explained this analogously:

"If you ask Coke and Pepsi to sit down and figure out nicely, they would laugh out and would say we don't want to figure everything out. Coke don't want Pepsi in the market and Pepsi don't want Coke in the market." [N4PNGO20200205]

Owing to this situation, few of the respondents supported the idea of role distributions among national and provincial partners (both public and private) so that pooled money is distributed based on their roles, hence promoting resource efficiency. 


\section{Discussion}

Having an efficient PHC system is a key aspect of sustaining the TB control initiatives at the primary care level in Pakistan. Utilization of existing resources, integration of services and capacity-building of health care providers are some examples. Moreover, stakeholder engagement and management should be guided by the national strategy, while recognizing community as an important stakeholder.

Inclusive planning, in which the government of Pakistan is a prime stakeholder, is critical for the sustainability of TB control efforts. The WHO has recognized the importance of government and community and defined sustainability as the ability of a project to continue delivering services with high treatment coverage, integration into existing health care services, strong community ownership and communityand government-driven resource mobilization (14). However, respondents expressed concern over the lack of involvement of communities in the planning process. The capacity of the community to continue with programmes is also seen as favourable to their sustainability $(15,20)$. Financial support is an important factor in enhancing the community's capacity to sustain the programme. For example, in Myanmar the contribution of local nongovernmental organizations fell due to the diminishing involvement of community members in the absence of a payment or financial support mechanism (21).

Insufficient government funding allocation increases dependence on donors (e.g. the Global Fund) for even basic services such as TB drugs. The same trend has been noted in many other developing countries, putting sustainability at risk (22). Similarly, policy-makers in Pakistan see the donor's influence on priority-setting negatively for both policy formulation and programme implementation (23).

There is a recognition that strengthening at the PHC level will help in sustaining existing TB control efforts in Pakistan as in $90 \%$ of TB cases at the national level, the contact is with the private sector, forts including the community-level informal sector (24). China has set an example in the fight against TB because of its increasing focus on the PHC system (25).

Despite the recognition of the importance of research, lacking a research agenda at the national level is a concern for formulating evidence-informed resource allocation decisions. The need for increased funding on research and development was accepted at a high-level meeting of the UN (26). Similarly, the need for increasing the research capacity and utilizing the evidence for various decisions in a more sustained and effective manner are also stressed (27).

Sustainability of health interventions is needed to allow the assessment of the long-term effects of health interventions (28) and to enable the detection of changes in community health status (29). There is a need to ensure a sustained funding mechanism to sustain evidence-supported interventions (30). Therefore, prioritizing assessment of the sustainability of the $\mathrm{TB}$ control programme is essential for the efficiency of the programme.

\section{Conclusion}

There is a clear need for investing more in sustaining the TB control programme at the primary health care level in Pakistan. Financial resources alone will not help achieve sustainability. Rather fostering an enabling operational environment through legislation and regulations, utilizing existing resources and expanding the network of providers at the PHC level are also needed. In consideration of these factors, inclusive planning with various government functionaries and communities, and increasing spending on research, cost-effective testing and evidence-informed innovation are all pivotal for sustaining the programme. Going forward, there should be an increased focus on innovation and research for guiding relevant investment and management decisions aimed at improving the efficiency of the programme at the PHC level.

Funding: None.

Competing interests: None declared.

\section{Le point de vue des praticiens de santé publique sur la pérennité du programme de lutte contre la tuberculose au niveau des soins de santé primaires au Pakistan}

\section{Résumé}

Contexte: Dans les contextes où les ressources sont limitées, les programmes nationaux de lutte contre la tuberculose sont fortement tributaires de fonds externes, ce qui peut compromettre la pérennité des programmes. Il existe un besoin reconnu d'élaborer des orientations concernant la programmation durable des initiatives actuelles de lutte contre la tuberculose.

Objectifs : La présente étude avait pour but d'explorer le point de vue des praticiens de santé publique sur la pérennité des initiatives de lutte contre la tuberculose au Pakistan au niveau des soins de santé primaires (SSP).

Méthodes: Grâce au recours à une épistémologie interprétative, des entretiens approfondis en ligne ont été menés avec dix praticiens de la santé publique ayant une expérience en tant que planificateurs de ressources dans le programme de lutte contre la tuberculose au Pakistan. L'analyse thématique de contenu a été utilisée pour les données textuelles en tant qu'approche analytique. 
Résultats : Trois thèmes ont été dérivés de façon inductive de l'analyse thématique : la participation communautaire, la collaboration avec les parties prenantes et l'utilisation efficace du système de SSP. La participation communautaire était un facteur déterminant dans le maintien des initiatives de lutte contre la tuberculose. Ce constat a été attribué à la nature de la maladie et au comportement prévalent en matière de recours aux soins. La collaboration avec les parties prenantes était associée aux accords de financement entre les partenaires publics et privés; elle était considérée comme importante dans la façon dont les nouvelles initiatives peuvent être intégrées à la structure habituelle. Dans l'ensemble, il a été jugé essentiel de disposer d'un système efficace de soins de santé primaires pour pérenniser les initiatives actuelles de lutte contre la tuberculose au niveau des soins de santé primaires au Pakistan.

Conclusion: La promotion d'un environnement opérationnel favorable par le biais de réglementations, le soutien apporté à l'utilisation des ressources existantes, l'élargissement du réseau de prestataires, la planification inclusive, l'augmentation des dépenses consacrées à la recherche et aux dépistages d'un bon rapport coût-efficacité sont essentiels pour soutenir les initiatives de lutte contre la tuberculose.

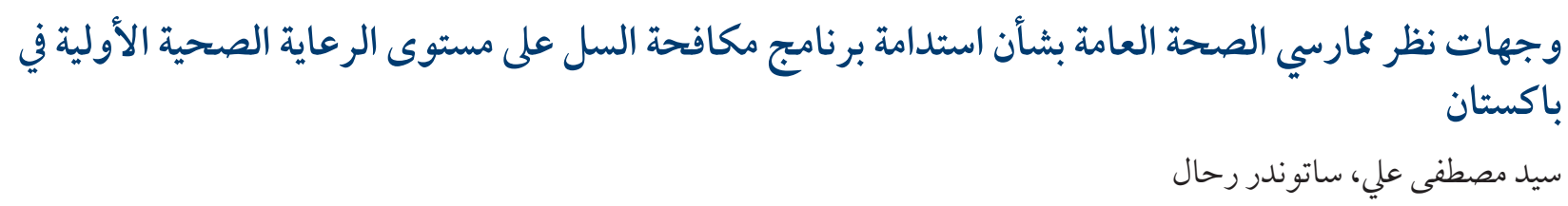

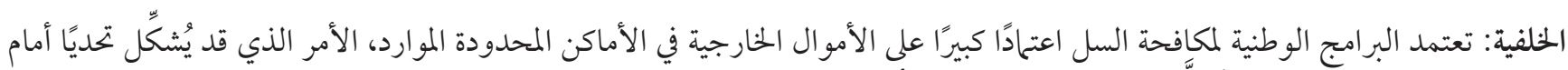

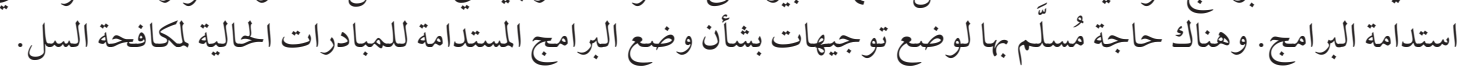

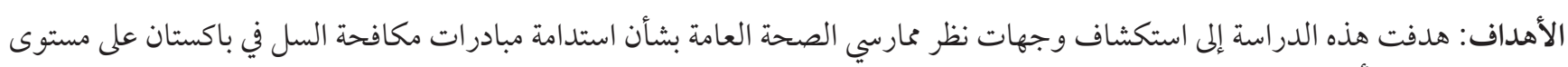

$$
\begin{aligned}
& \text { الرعاية الصحية الأولية. }
\end{aligned}
$$

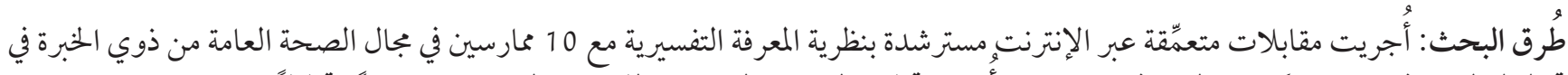

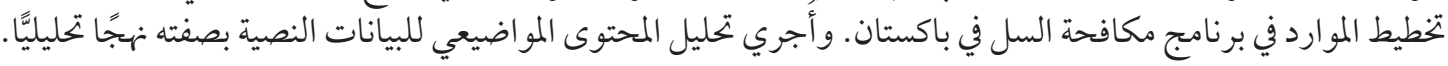

\section{References}

1. Global tuberculosis report. Geneva: World Health Organization; 2020.

2. Metzger P, Baloch NA, Kazi GN, Bile KM. Tuberculosis control in Pakistan: reviewing a decade of success and challenges. East Mediterr Health J. 2010;16(Suppl.):S47-53. PMID: 21495588

3. Pluye P, Potvin L, Denis J-L. (). Making public health programs last: conceptualizing sustainability. Evaluation Program Plann. 2004;27(2):121-33. https://doi.org/10.1016/j.evalprogplan.2004.01.001

4. Scheirer MA, Dearing JW. An agenda for research on the sustainability of public health programs. Am J Public Health. 2011 Nov;101(11):2059-67. doi:10.2105/AJPH.2011.300193

5. Walugembe DR, Sibbald S, Le Ber MJ, Kothari A. Sustainability of public health interventions: where are the gaps? Health Res Policy Syst. 2019 Jan 15;17(1):8. doi:10.1186/s12961-018-0405-y

6. Altman DG. Challenges in sustaining public health interventions. Health Educ Behav. 2009 Feb;36(1):24-8; discussion 29-30. doi: 10.1177/1090198107299788

7. Schell SF, Luke DA, Schooley MW, Elliott MB, Herbers SH, Mueller NB, et al. Public health program capacity for sustainability: a new framework. Implement Sci. 2013 Feb 1;8:15. doi:10.1186/1748-5908-8-15

8. A vision for primary health care in the 21st century: towards universal health coverage and the Sustainable Development Goals. Geneva: World Health Organization, \& United Nations Children's Fund; 2018 (https://apps.who.int/iris/handle/10665/328065, accessed 7 April 2021). 
9. Khan WM, Smith H, Qadeer E, Hassounah S. Knowledge and perceptions of national and provincial tuberculosis control programme managers in Pakistan about the WHO Stop TB strategy: a qualitative study. JRSM Open. 2016 Dec 1;8(1):2054270416675084. doi:10.1177/2054270416675084

10. Walsham G. Interpreting information systems in organizations. New York:John Wiley \& Sons, Inc; 1993.

11. Brinkmann S, Kvale S. InterViews: learning the craft of qualitative research interviewing, 3rd ed. Thousand Oaks: SAGE Publications, Inc; 2014

12. Jupp V. The SAGE dictionary of social research methods. Thousand Oaks: SAGE Publications, Ltd; 2006 (https://doi. org/10.4135/9780857020116).

13. Patton M. Qualitative research and evaluation methods, 3rd ed. Thousand Oaks: SAGE Publications, Inc; 2002.

14. Guidelines for conducting an evaluation of the sustainability of CDTI projects. Geneva: World Health Organization; 2004 (https://www.who.int/apoc/publications/guidelinesevalsustainabilitycorrectedversionsepto4.pdf, accessed 7 April 2021).

15. Mann S, Byrnes T. Capacity building and community enrichment: evaluation for sustainability. Austr J Primary Health. 1999;5(3):43. doi:10.1071/PY99032

16. Peterson, B. L. Thematic analysis/interpretive thematic analysis. In: Matthes J, Davis CS, Potter RF, eds. The international encyclopedia of communication research methods. Hoboke, New Jersey: Wiley; 2017:1-9 (https://doi.org/10.1002/9781118901731. iecrmo249).

17. Kringos DS, Boerma W, van der Zee J, Groenewegen P. Europe's strong primary care systems are linked to better population health but also to higher health spending. Health Aff (Millwood). 2013 Apr;32(4):686-94. doi:10.1377/hlthaff.2012.1242

18. Ali SM, Anjum N, Ishaq M, Naureen F, Noor A, Rashid A, et al. Community knowledge about tuberculosis and perception about tuberculosis-associated stigma in Pakistan. Societies. 2019;9(1):9. doi:10.3390/soc9010009

19. Implementing the end TB strategy: the essentials. Geneva: World Health Organization; 2015.

20. Farmer J, Lauder W, Richards H, Sharkey S. Dr John has gone: assessing health professionals' contribution to remote rural community sustainability in the UK. Soc Sci Med. 2003 Aug;57(4):673-86. doi:10.1016/s0277-9536(02)00410-0

21. Maung HM, Saw S, Isaakidis P, Khogali M, Reid A, Hoa NB, et al. The contribution of a non-governmental organisation's community based tuberculosis care programme to case finding in Myanmar: trend over time. Infect Dis Poverty. 2017 Apr 3;6(1):51. doi:10.1186/s40249-017-0253-y

22. Towards equitable access and sustainable TB control - annual plan. The Hague: KNCV Tuberculosis Foundation; 2014 (https:// www.kncvtbc.org/uploaded/2015/09/annual_plan_2014_for_website1.pdf, accessed 7 April 2021).

23. Khan MS, Meghani A, Liverani M, Roychowdhury I, Parkhurst J. How do external donors influence national health policy processes? Experiences of domestic policy actors in Cambodia and Pakistan. Health Policy Plan. 2018 Mar 1;33(2):215-23. doi:10.1093/ heapol/czx145

24. Fatima R, Haq MU, Yaqoob A, Mahmood N, Ahmad KL, Osberg M, et al. Delivering patient-centered care in a fragile state: using patient-pathway analysis to understand tuberculosis-related care seeking in Pakistan. J Infect Dis. 2017 Nov 6;216(Suppl. 7):S733-9. doi:10.1093/infdis/jix380

25. Jia Z, Cheng S, Wang L. Tuberculosis control in China: striving for sustainability. Lancet. 2012 Jun 9;379(9832):2149. doi:10.1016/ So140-6736(12)60942-8

26. Sakamoto H, Lee S, Ishizuka A, Hinoshita E, Hori H, Ishibashi N, et al. Challenges and opportunities for eliminating tuberculosis - leveraging political momentum of the UN high-level meeting on tuberculosis. BMC Public Health. 2019 Jan 16;19(1):76. doi:10.1186/s12889-019-6399-8

27. A draft global strategy for TB research and innovation. Geneva: World Health Organization; 2019.

28. Michie S, West R, Sheals K, Godinho CA. Evaluating the effectiveness of behavior change techniques in health-related behavior: a scoping review of methods used. Transl Behav Med. 2018 Mar 1;8(2):212-24. doi:10.1093/tbm/ibxo19

29. Thompson B, Lichtenstein E, Corbett K, Nettekoven L, Feng Z. Durability of tobacco control efforts in the 22 Community Intervention Trial for Smoking Cessation (COMMIT) communities 2 years after the end of intervention. Health Educ Res. 2000 Jun;15(3):353-66. doi:10.1093/her/15.3.353

30. Proctor E, Luke D, Calhoun A, McMillen C, Brownson R, McCrary S, et al. Sustainability of evidence-based healthcare: research agenda, methodological advances, and infrastructure support. Implement Sci. 2015 Jun 11;10:88. doi:10.1186/s13012-015-0274-5 